\title{
Roles of Tbx4 in the Lung Mesenchyme for Airway and Vascular Development
}

\author{
Keiko Uchida, Yu Yoshida, Kazuki Kodo, \\ and Hiroyuki Yamagishi
}

\author{
Keywords \\ Lung $\cdot$ Mesenchyme $\cdot$ Vascular development $\cdot$ Transcription factor
}

The T-box family genes are evolutionarily conserved transcription factors. In particular, Tbx4 and Tbx 5 are closely conserved and play crucial roles in development and organogenesis. Tbx 4 is essential for hindlimb and allantoic vessel formation [1]. Our data show that it is also highly expressed in the lung mesenchyme (Fig. 8.1), initially expressed at embryonic day (E) 9.25 and later expressed throughout murine embryogenesis [2].

Lung mesenchyme is stromal tissue that surrounds the epithelium and consists of undifferentiated progenitor cells, which give rise to various cell types, such as smooth muscle, cartilage, fibroblasts, endothelium, pericytes, and mesothelium. Although the behavior of epithelial progenitors has been elucidated, much less is known about the identity and behavior of mesenchymal progenitors in the lungs. Mesenchymal cells are generally thought to have highly proliferative, migratory, and multipotent potential. Lung-specific mesenchymal Tbx4 and Tbx5 deficiency revealed that these transcription factors cooperatively regulated branching morphogenesis, likely through the activation of fibroblast growth factor (Fgf) 10

\footnotetext{
K. Uchida $(\bowtie)$

Department of Pediatrics, Keio University School of Medicine, Shinjuku, Tokyo, Japan

Health Center, Keio University, Minato, Tokyo, Japan

e-mail: keiuchid@keio.jp

Y. Yoshida $\cdot$ K. Kodo

Department of Pediatrics, Keio University School of Medicine, Shinjuku, Tokyo, Japan

H. Yamagishi $(\bowtie)$

Division of Pediatric Cardiology, Department of Pediatrics,

Keio University School of Medicine, Tokyo, Japan

e-mail: hyamag@keio.jp

(C) The Editor(s) (if applicable) and The Author(s) 2020

T. Nakanishi et al. (eds.), Molecular Mechanism of Congenital Heart Disease

and Pulmonary Hypertension, https://doi.org/10.1007/978-981-15-1185-1_8
} 

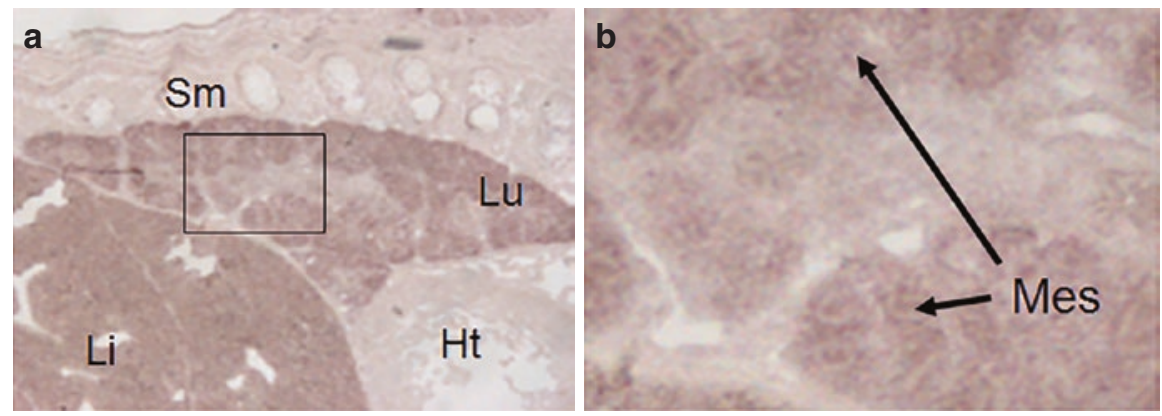

Fig. 8.1 Tbx4 is expressed in the lung mesenchyme. Section ISH with Tbx4 anti-sense riboprobe (a low magnification, b high magnification of the square area in a) shows Tbx4 is expressed throughout the lung mesenchyme at E14.5. Ht heart, Li liver, Lu lung, Mes mesenchyme, Sm somite

signaling during the lung development [2]. Tbx4 is detectable at earlier stages of lung development compared to other mesenchymal transcription factors [3], suggesting that Tbx4 functions upstream from them. Cell lineage tracing using transgenic mice harboring the lung-specific mesenchyme enhancer (LME) from the mouse Tbx4 locus (Tbx4-LME)-specific Cre transgene showed that Tbx4-expressing cells give rise to all cell types of the lung mesenchyme [3]. Although it remains controversial whether they become pulmonary vascular endothelial cells or not, Tbx4 lung enhancer-driven Tet-On inducible Cre reporter mice showed that both of pulmonary endothelium and vascular smooth muscle were targeted from E11.5; it was also found that the expression level of $\mathrm{Tbx} 4$ decreased once the pulmonary vascular cells were differentiated [4].

From these reports, Tbx4 in undifferentiated mesenchymal progenitor cells may be involved in the formation of both airways and vessels in the lungs. The roles of Tbx4 in the lung mesenchyme may pave the way for novel mechanisms underlying pulmonary vascular development.

Acknowledgment This work was supported by JSPS KAKENHI Grant Numbers JP17K10153 and JP23591583 to KU, and $16 \mathrm{H} 05359$ to HY.

\section{References}

1. Naiche LA, Papaioannou VE. Tbx4 is not required for hindlimb identity or post-bud hindlimb outgrowth. Development. 2007;134:93-103.

2. Arora R, Metzger RJ, Papaioannou VE. Multiple roles and interactions of Tbx4 and Tbx5 in development of the respiratory system. PLoS Genet. 2012;8:e1002866.

3. Kumar ME, Bogard PE, Espinoza FH, et al. Defining a mesenchymal progenitor niche at single-cell resolution. Science. 2014;346:1258810.

4. Zhang W, Menke DB, Jiang M, et al. Spatial-temporal targeting of lung-specific mesenchyme by a Tbx4 enhancer. BMC Biol. 2013;11:111. 
Open Access This chapter is licensed under the terms of the Creative Commons Attribution 4.0 International License (http://creativecommons.org/licenses/by/4.0/), which permits use, sharing, adaptation, distribution and reproduction in any medium or format, as long as you give appropriate credit to the original author(s) and the source, provide a link to the Creative Commons license and indicate if changes were made.

The images or other third party material in this chapter are included in the chapter's Creative Commons license, unless indicated otherwise in a credit line to the material. If material is not included in the chapter's Creative Commons license and your intended use is not permitted by statutory regulation or exceeds the permitted use, you will need to obtain permission directly from the copyright holder. 